\title{
Joh. H. Sikemeier
}

Author(s): J. A. W.

Source: Tijdschrift der Vereeniging voor Noord-Nederlands Muziekgeschiedenis, Deel 10, 3de Stuk (1922), pp. 198-203

Published by: Koninklijke Vereniging voor Nederlandse Muziekgeschiedenis (KVNM)

Stable URL: http://www.jstor.org/stable/947810

Accessed: 19-06-2016 10:31 UTC

\footnotetext{
Your use of the JSTOR archive indicates your acceptance of the Terms \& Conditions of Use, available at

http://about.jstor.org/terms
}

JSTOR is a not-for-profit service that helps scholars, researchers, and students discover, use, and build upon a wide range of content in a trusted digital archive. We use information technology and tools to increase productivity and facilitate new forms of scholarship. For more information about JSTOR, please contact support@jstor.org.

Koninklijke Vereniging voor Nederlandse Muziekgeschiedenis (KVNM) is collaborating with JSTOR to digitize, preserve and extend access to Tijdschrift der Vereeniging voor NoordNederlands Muziekgeschiedenis 


\section{JOH. H. SIKEMEIER}

Den 22en Juni j.l. werd op de Algemeene Begraafplaats te Rotterdam, in den volksmond nog steeds Crooswijck geheeten, een eenvoudig gedenkteeken onthuld ter blijvende herinnering aan den man, wiens stoffelijk overschot daar juist anderhalf jaar te voren was ter ruste gelegd, een obelisk -in zandsteen gehouwen met niets ter versiering dan de bronzen beeltenis "en médaillon" van hem wien de\%e hulde gold en daaronder, met zijnen naam de toevoeging : „van zijne vrienden en vereerders". Eenvoud bij goeden smaak kenmerkt dit door Miedema ontworpen gedenkteeken, waarvan eene afbeelding hierbij wordt opgenomen; eenvoudig doch van oprechtheid getuigend, was ook de plechtigheid der onthulling. Die oprechtheid, die eenvoud spraken echter eene duidelijke taal; wie daar om Sikemeier's graf verecnigd stonden en een door Bernard Diamant geleid vrouwenkoor op sublieme wijze onder meer ook Schubert's „Ueber allen Gipfeln ist Ruh” hoorden vertolken, voelden zich opgeheven tot die reine sfeer van het ware, goede en schoone, in wier dienst SiкEmeier zijn leven lang zich zulk een waardig priester heeft getoond.

Ter herinnering aan dien merkwaardigen man hier enkele regels te mogen neerschrijven, was voor mij een cervolle taak, welke echter met schroom werd aanvaard in het besef, dat mijn leekepen in het gunstigste geval niet meer dan een "leekepraatje" zou vermogen te geven. Moge mijne oprechte waardeering voor den eminenten kunstenaar die SIrEmEIrR was en het verlangen daarvan openlijk te getuigen eene verontschuldiging zijn voor mijne wellicht te groote vrijmoedigheid.

Johannes Hendrikus Sikemeier is in 1838 te Amsterdam geboren; zijn vader oefende er het beroep van kleermaker uit, zijne moeder was eene geziene piano-onderwijzeres, die reeds zéér vroegtijdig haar veelbelovenden jongen het eerste onderricht gaf. En of hij snelle vorderingen 


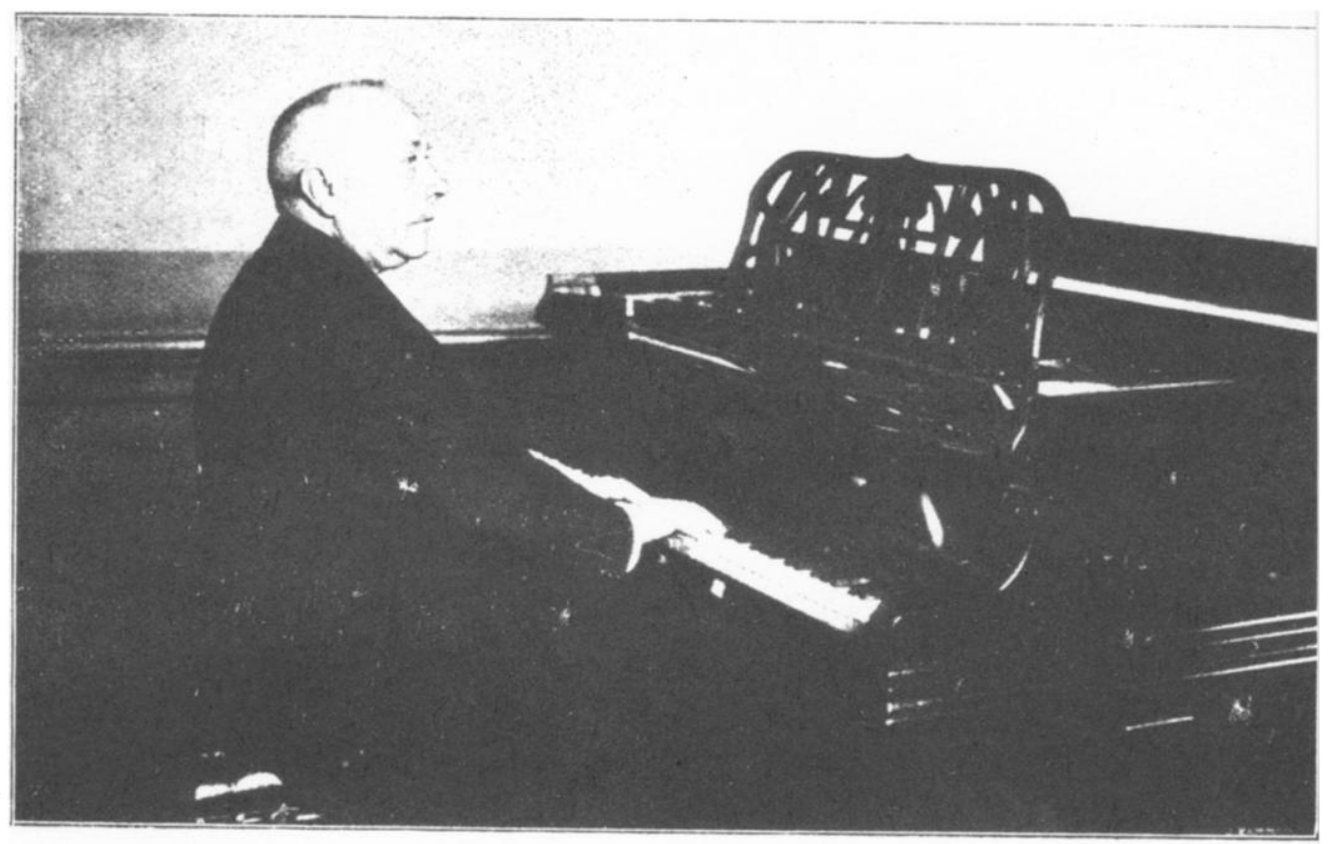

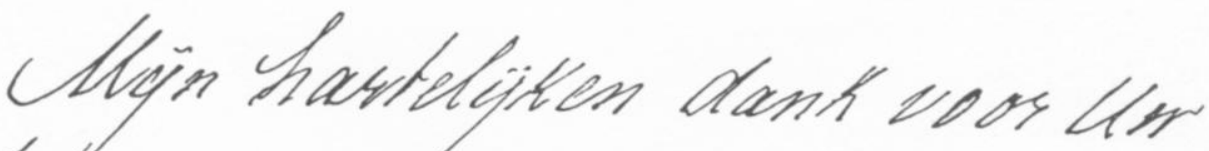

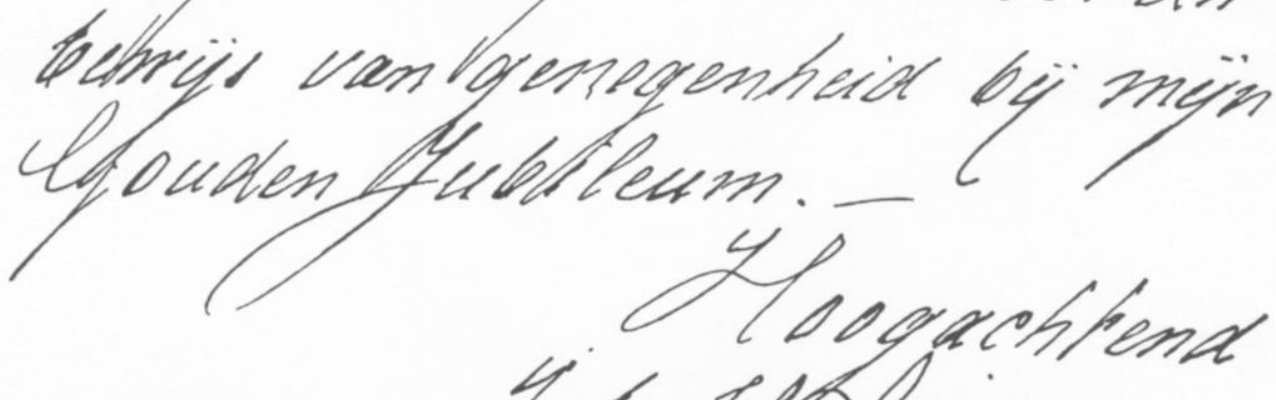
tothiturn Sept: igib.

This content downloaded from 139.184.14.159 on Sun, 19 Jun 2016 10:31:05 UTC All use subject to http://about.jstor.org/terms 
maakte! Stel $U$ den achtjarigen dreumes voor zich oefenend op een van Mendelssohs's pianoconcerten, wiens heimelijk verlangen intusschen was, in een stil hoekje zich bezig te houden met het mooie speelgoed van z'n vriendjes, bij wier ouders hij te gast werd gevraagd, onbewust van wat er in hem bloeide en groeide! Spoedig daarop vertrok het gezin naar Rotterdam; de ziekelijke toestand der moeder noodzaakte den zoon mede den kost te helpen verdienen, en zoo zien we den „kleinen JohanNes” zijn eerste schreden richten naar de openbaarheid in het destijds bestaande, goed bezochte koffiehuis Koolen achter de Groote Kerk, alwaar hij des avonds zijne pianistische talenten ten beste gaf. Hij woonde toen met zijn ouders op het Hofje van Malefeit aan den Oostzeedijk en, teekenende bijzonderheid voor dien tijd, was reeds in het bezit van een eigen piano, toenmaals een lang niet alledaagsche weelde.

Zijn optreden in den huize Koolen en ook elders trok reeds spoedig de aandacht en had ten gevolge, dat eenige kunstlievende en welgestelde Rotterdammers Sikemeicr in staat stelden, de lessen aan het Conservatorium te Brussel te volgen. Het is wel leerzaam, in de Hollandsche Revue van 1916 nog eens na te lezen wat aldaar over zijne Brusselsche periode onder meer verteld wordt. Chopin, de meester, waartoe de leerling zich allereerst voelde aangetrokken, moet er min of meer als een "verdwaasde bohémien" gegolden hebben en professor Godrseau, Sikemeier's leermeester, van Chopiv's muziek hebben getuigd: „C'est de la musique fatiguée..... ce sont des compositions maladives"..... En Beethoren, zoo lezen we verder, kende men in dit millieu slechts van hooren zeggen, om van Schumann maar te zwijgen, zoodat onze Johannes eerst op 17jarigen leeftijd (in 1855) en dat nog toevalliger wijze, door het optreden van Louis Brassin, die met een strijkkwartet Schumann's klavierkwintet te Brussel kwam spelen, met den beroemden negentiendeeeuwschen romanticus kennis makkte.

Hoe dit zij, Sikemeier heeft zich te Brussel aan het Conservatorium en ook daar buiten (hij werkte sedert 1855 herhaaldelijk samen met Brassin en waarschijnlijk ook met KUFFERATH) tot een uitstekend onderlegd pianist kunnen vormen; in 1857, dus op negentienjarigen leeftijd verliet hij dit muziekinstituut met een "Premier Prix... grande distinction"; reeds toen bleek hij een meester te zijn in het van het blad lezen. 
Vrij spoedig daarna is Sikemeier naar Rotterdam teruggekeerd en heeft er zich voor goed gevestigd. De goede reputatie uit Brussel mede. gebracht bezorgde hem spoedig een aantal lessen in de toonaangevende kringen en weldra was hij in menig gezin het "enfant chéri", zooals ouderen van dagen zich dit nog goed herinneren. Dat was voor hem het begin van een lang, gelukkig en vruchtbaar kunstenaarsleven. En ook zijn lijfspreuk had kunnen luiden : „repos ailleurs”; de taak, die deze tot op hoogen leeftijd kerngezonde man zich dagelijks stelde, was groot en dagelijks volvoerde hij die met onbezweken frischheid en kracht. Dit te kunnen gedurende een lang menschenleven is op zich zelf reeds een geluk; doch hoeveel grooter, hoeveel rijker wordt 's menschen levensinhoud, wanneer hij zijn arbeids-energie niet slechts voor zich zelf weet dienstbaar te maken, doch daarmede ook bij anderen die arbeidsvreugde weet op te wekken, die alleen voert naar het hoogst bereikbare. En in dat opzicht is SiкемEгEn wel zeer gelukkig geweest; zijne vele discipelen uit vroeger en later tijd, waaronder talrijke die naam hebben gemaakt, zullen hun leermeester zeker ook in dit opzicht dankbaar bljven gedenken.

In 1866, tijdens het directeurschap van Woldemar BargiËL, is SikeMEIER aan de Muziekschool der Rotterdamsche Toonkunst Afdeeling gekomen en gedurende een halve eeuw heeft die instelling dezen eminenten paedagoog onder hare leerkrachten mogen rekenen. Onwillekeurig gaat de herinnering terug naar de school op de Nieuwe Markt, waar hij al dien tijd gearbeid heeft, waar hij zoo menigen collega heeft zien komen en gaan Zal ik de namen van enkelen der oude garde noemen: van Woldemar BargiëL, de beide De Lange's, vader en zoon, Theodoor Verhey, Emandel Wirth, Oscar Eberle (de vader), M. Meerlo, G. van de Sandt, Friedrich Gernsheim? Allen heeft hij ze gekend, met verschillenden hunner samengewerkt, en met nog vele anderen. Daar, op de bovenste verdieping van het "Boterhuis”, vier trappen hoog, was het zoogenaamde kunstklassen-lokaal. Een vrij donkere gang met aan de eene zijde niets dan geel-geverfde kast- (en andere) deuren voerde er heen en een dubbele deur, waarvan de eene helft steeds gesloten bleef, gaf er den toegang. Een bepaald gezellig voorkomen had die zaal niet, 't was alles erg zakelijk. Drie witgekalkte muren, de vierde hoofdzakelijk 
door ook alweder geel-geverfde kasten ingenomen warboven een breedgestrekt tralie-venster, dat een "riant" uitzicht verleende op de omringende daken, dakvensters en schoorsteenen, onder het tralie-venster een groote uitschuiftafel, zooals men die vroeger veelvuldig in burgergezinnen aantrof, een in eenigszins vervallen staat verkeerende groote antieke kast (na grondige restauratie is ze een sieraad geworden van de tegenwoordige directeurskamer der school aan de Van der Duynstraat) een vrij groot aantal rieten stoelen, twee vleugels, een Steinway en een Erard, de laatste afkomstig uit den boedel van wijlen J. R. Smalt, den bekenden Toonkunst-secretaris eener vroegere periode, aan een der wan. den een borstbeeld op console van BEethoven, dit een en ander vormde behoudens een paar kapstokken en een parapluiebak den eenvoudigen inventaris der localiteit, waar binnen vele geslachten van beiderlei kunne (de nzwakke" was er meestal de sterkst vertegenwoordigde) hunne opleiding hebben genoten.

In die sobere omgeving heeft ook Sik EMEIER al die jaren zijne paedagogische gaven op kwistige wijze uitgedeeld. En met welk een resultaat! „Juist nu”, schreef mij onlangs een zijner voortreffelijkste oud-leerlingen, thans zelf een klavierspeler en paedagoog van flinke reputatie, „voel ik neerst recht hoe deze man voor mij van veel waarde is geweest. Dc "wijze waarop hij les gaf, had altijd iets genoegelijks, nimmer een „driftige bui, en toch voelde ik dat er àlles van hem uitging. Men "schaamde zich te komen les nemen, wanneer niet alles in de puntjes „af was, en juist dáárin, geloof ik, schuilde voor een groot deel Sikk„MEIER's kracht als leeraar. SikrmeIER leerde iedereen werken en spelen; „zelfs de minder muzikaal aangelegde leerlingen voldeden tot op zekere "hoogte toch, omdat het technisch gedeelte van hun spel steeds in orde was." Met recht kan gezegd worden, dat Sikemeier eene school heeft gevormd, al zijne leerlingen onderscheidden zich behalve door vele andere goede hoedanigheden steeds door een zekere distinctie, waarvan hij in het bïzonder het geheim kende. En hoe hï het verstond, de meer- en meestbegaafden technisch zoowel als in muzikaal opzicht op te voeren naar de zonnige middaghoogte der kunst, het behoeft hier niet nogmaals herhaald te worden; namen als Dirk Schäfer, Frieda Kindler, Adolf Waterman, Piet de WaArdt, Louis Schnitzler, Anton Kaltwasser, 
Garoline lankhout, Goba Rijneke, j'en passe et des meilleurs, sprcken voor zichzelf en ook Bernard Diamant, George Rijken en de onlangs overleden JAN RuJKen zijn voor het klavierspel, en dat niet alleen, SikemEIER's leerlingen geweest.

Sikemeier, die voor sommigen oogenschijnlijk zoo koele en afgemeten man, was voor wie hem nader stonden, een hartelijke vriend, in de allereerste plaats voor zijn élèves; in blijde zoowel als in droeve oogenblikken leefde hij met hen mede, stond hij hun waar hij kon ter zijde. Een enkel voorbeeld: een brief van zijne hand uit het jaar 1907, gericht aan cene intieme vriendin, ligt voor me; SiкемEier schrijt daar met enthousiasme over een zijner leerlingen, die dien winter op het "kunstklasse examen" der Toonkunst-Muriekschool speelde en citeert zijn programma: „Liebestraum-Nocturne van LiszT, Etude van den Rus ${ }_{n}$ BLumenfeld voor de linkerhand alléén, gecomponeerd (voegt hij er bij) , voor Godowsky, verder de zesde Rhapsodie Hongroise van Liszr, "Carreno's Octaven paradestuk!", „nog al aardig”, zoo vervolgt hij, "zulk een echt Godowsky-programma voor een Ieerling van de Muziek"school; in Arnhem heeft hij onlangs de Buurenferd-Etude gespeeld, ,het publiek van de achterste helft der zaal stond overeind om zich te "overtuigen of het wel ééne hand was, die zulke orchestrale volheid uit „de piano haalde!" Nietwaar, daar spreekt naast gerechtvaardigden trots ook mede-leven uit die woorden; ik mag nu wel verklappen, dat ADolF Waterman die fameuse leerling was en ik ben er bijna zeker van, dat de meester er de reis naar Arnhem voor heeft overgehad om van het succes van zijn leerling mede te genieten.

En waar droefheid of rouw was of soms geldelijke zorgen drukten en Siremeier kwam het te hooren, daar ook bood hij hulp of troost, daar vonden zijn leerlingen, die een geliefden doode te betreuren hadden, hun leermeester als een trouwhartig vriend aan hunne zijde om hun moed en opbeuring in te spreken. Om SiKEMEIER goed te leeren kennen, moest men hem waarnemen 'tzij te midden zijner élèves, 'tzij in den intiemen kring. Daar ook ontplooide zich zijn somtijds zoo gesloten natuur, was hij de gulle gastheer, de vroolijke, vaak onderhoudende kouter, die vertelde van zijne ervaringen, van zijne ontmoetingen met beroemde kunstenaars, met Brahms, Rubinstein. Mevrouw Giara 
Schusian, Henir Lrrorff en zoovele anderen : daar, in zijn mooie huis aan de Schiekade, dat hij sedert zijn op later leeftijd gesloten huwelijk bewoonde en waar zijn lieve vrouw ook de oogen voor altijd sloot, daar, aan een zijner kostbare vleugels gezeten, was hij steeds de warm voelende kunstenaar, gaf hij met milde hand uit den onuitputtelijken schat, welke zijn bijna onbegrensd répertoire vormde; van BaCH tot BEETHoven, van Liszt, Schumann en Brahms tot de moderne Russen en de jongFransche school, van dat alles en nog veel meer was hij op de hoogte, de geheele piano-literatuur had hij als het ware in zich opgenomen en nimmer zag men een notenblad op den lessenaar wanneer hij voorspeelde; zijn muzikaal geheugen moet wel iets zeldzaam compleets zijn geweest. Ook hem te zien spelen was een apart genoegen, zijne rustige houding, zijn in één woord elegant spel vormde eene bekoring op zich zelf. En wanneer hij dan zijn kleinen kring van hoorders onafgebroken gedurende soms meer dan twee volle uren had weten te boeien en hij stond eindelijk van den vleugel dien hij bespeeld had op, dan ging dit menigmaal vergezeld van de woorden : „ziezoo, dien hebben wij eens weer naar zijn gezondheid gevraagd". SikEmeier had meer van die hem eigen gezegden; wanneer bijvoorbeeld het gesprek over zijn dag-indeeling liep: altijd heel vroeg op, een koud stortbad, het ontbijt en een kleine wandeling (dit alles was reeds vóór acht uur afgedaan) en daarna aan het klavier voor studie-arbeid, ,maar eerst bidden", placht hij dan te laten volgen, daarmede doelende op zijne dagelijksche, zuiver mechanische vingeroefeningen, aan wier volmaking hij ook zijn leven lang, een brief van hem toen hij de vijfenzeventig reeds achter den rug had getuigt er van, is blijven arbeiden.

Deze korte terugblik op SiKEMEIER's levensgang maakt allerminst aanspraak op zij het slechts eene betrekkelijke volledigheid; slechts over datgene heb ik iets willen zeggen, waarin voor mij, en naar ik meen ook wel voor anderen, Srkemeier's grootste en blijvende beteekenis ligt ten opzichte van het Rotterdamsche muziekleven, waarin hij gedurende een half eeuwgetijde een figuur is geweest, die naar meer dan ééne zijde op den voorgrond is getreden. Zijn roem als klavierpaedagoog leeft voort in zijne talrijke discipelen.

Rotterdam, Augustus 1921.

J. A. W, 